\title{
MARXISMO E ESPERANÇA: ERNST BLOCH, PENSADOR REVOLUCIONÁRIO
}

Michael Löwy ${ }^{1}$

\section{Resumo}

Ernst Bloch, pensador marxista, dedicou toda a sua vida à ideia de utopia. Esta compõe o coração da reflexão de Bloch desde seus primeiros escritos, O espírito da utopia (de 1918) e Thomas Münzer: teólogo da revolução (de 1921). Referindo-se aos seus primeiros escritos, Bloch os definia como romântico-revolucionários. O romantismo revolucionário do pensador alemão alcança sua mais importante contribuição em $O$ princípio esperança, o livro mais importante de Ernst Bloch e, sem dúvidas, uma das obras mais importantes do pensamento emancipatório do século XX. Tal livro enciclopédico representa uma imensa e fascinante viagem pelo passado, em busca das imagens do desejo e das paisagens da esperança. É válido ressaltar que por "romantismo" entendemos não somente uma escola literária do início do século XIX, mas uma vasta corrente cultural de protesto em nome de certos valores sociais e culturais do passado, contrária à civilização capitalista moderna. Nesse contexto, não se trata de uma nostalgia do passado, mas de resgatá-lo na crítica do presente, e rumo ao futuro possível. Não casualmente a tematização da utopia se vincula a uma ontologia da possibilidade que caminha na direção de um conceito dialético de realidade na direção do marxismo. Assim, pretendemos refletir, no presente texto, como esse resgate da utopia vai de encontro com uma ontologia do ainda-não-ser, na base da qual se afirma que o mundo, tal como existe, é falso. Em suma, pretendemos elucidar alguns dos conceitos centrais da filosofia da esperança e da utopia concreta de Ernst Bloch, no interior de uma contribuição no âmbito do marxismo.

Palavras-chave: Marxismo. Utopia. Romantismo revolucionário. Possibilidade. Crítica do presente.

\section{MARXISM AND HOPE: ERNST BLOCH, REVOLUTIONARY THINKER}

\begin{abstract}
Ernst Bloch, a Marxist thinker, dedicated his whole life to the idea of utopia. This has been at the heart of Bloch's reflection since his early writings, The Spirit of Utopia (1918) and Thomas Münzer as Theologian of Revolution (1921). Referring to his early writings, Bloch defined them as romantic-revolutionaries. The revolutionary romanticism of the German thinker achieves his most important contribution in The Principle of Hope, the most important book by Ernst Bloch and, without a doubt, one of the most important works of emancipatory thought of the 20th century. This encyclopedic book represents an immense and fascinating journey through the past, in search of images of desire and landscapes of hope. It is worth noting that by "romanticism" we mean not only a literary school from the beginning of the 19th century, but a vast cultural current of protest in the name of certain social and cultural values of the past, contrary to modern capitalist civilization. In this context, it is not a question of a nostalgia for the past, but of rescuing it in the criticism of the present, and towards the possible future. Not by chance, the thematization of utopia is linked to an ontology of possibility that moves towards a dialectical concept of reality in the direction of Marxism. Thus, we intend to reflect in the present text how this rescue from utopia meets an ontology of the still-not-being, on the basis of which it is stated that the world as it exists, is false. Therefore, we intend to elucidate some of the central concepts of Ernst Bloch's philosophy of hope and concrete utopia, with a contribution within the scope of Marxism.
\end{abstract}

Keywords: Marxism. Utopia. Revolutionary romanticism. Possibility. Criticism of the present.

1 Texto traduzido do francês por Cícero Émerson do Nascimento Cardoso e Marta Maria Aragão Maciel. Emerson Cardoso é doutorando em Literatura, Teoria e Crítica literária pela UFPB. Marta Maciel é doutora em Filosofia pelo programa de doutorado integrado da UFPB/UFPE/UFRN, e tem realizado pesquisas acerca do pensamento social crítico, com ênfase na obra de Ernst Bloch. O resumo do presente texto foi elaborado pelos tradutores. O texto de Michael Löwy aqui disponibilizado foi publicado originalmente na Argentina, em coletânea organizada por Miguel Vedda: LÖWY, M. Utopía y romanticismo revolucionario en Ernst Bloch. In: VEDDA, Miguel (org.) Ernst Bloch - Tendencias y latencias de un pensamiento. Buenos Aires: Herramienta Ediciones, 2007, pp. 13-21. 
$\mathrm{Eu}$ tive a oportunidade de conhecer Ernst Bloch pessoalmente. Nosso encontro aconteceu em 1974, em seu apartamento em Tübingen, situado não longe da escola (o Stift) onde - como ele frequentemente amava lembrar em seus escritos -, em 1789, os jovens Hegel, Schelling e Hölderlin plantaram uma árvore da liberdade para festejar a Revolução Francesa. Ele estava já na idade de 89 anos, praticamente cego, mas de uma impressionante lucidez.

Entre suas observações, durante a nossa entrevista, houve uma que me afetou bastante e que resume a fidelidade obstinada de toda uma vida à ideia de utopia:

\begin{abstract}
O mundo, tal como existe, não é verdadeiro. Existe um segundo conceito de verdade, que não é positivista, que não é fundado sobre a facticidade (...), mas que é muito carregado de valor (Wertgelanden), como, por exemplo, no conceito "um amigo verdadeiro", ou na expressão de Juvenal Tempestas poética - quer dizer, uma tempestade tal como se dá no livro, uma tempestade poética, tal como a realidade jamais a conhece, uma tempestade levada até o fim, ou seja, uma tempestade radical. Logo, uma tempestade verdadeira, neste caso, em comparação com a estética e com a poesia; na expressão "um amigo verdadeiro", por comparação à esfera moral. E se isso não corresponde aos fatos - e, para nós marxistas, os fatos não são senão momentos reificados de um processo e nada mais, tanto pior para os fatos (um so schlimmer für die Tatsachen), como dizia o velho $\mathrm{Hegel}^{2}$.
\end{abstract}

O sonho acordado utópico está no coração da reflexão de Bloch desde seus primeiros escritos, O espírito da utopia, de 1918, e Thomas Münzer: teólogo da revolução, de 1921. Referindo-se aos seus primeiros escritos, e em particular ao Thomas Münzer, Bloch os definia como romântico-revolucionários. Eu penso que esta definição se aplica a toda a sua obra. Por "romantismo", eu não entendo somente uma escola literária do início do século XIX, mas uma vasta corrente cultural de protesto em nome de certos valores sociais e culturais do passado, contrária à civilização capitalista moderna, como um sistema de racionalidade quantificadora e de desencantamento do mundo ${ }^{3}$. Evidentemente, a nebulosa cultural romântica está longe de ser homogênea: nela encontramos uma pluralidade de correntes, desde o romantismo conservador e reacionário, que aspira à restauração dos privilégios e hierarquias do Antigo Regime, até o romantismo revolucionário, que integra as conquistas de 1789 (liberdade, democracia, igualdade) e para a qual a finalidade não é um retorno ao passado, mas um desvio através do passado comunitário em direção ao futuro utópico.

Evidentemente, é a esta última corrente que pertence Ernst Bloch, e neste espírito foram redigidos seus principais escritos, das obras de juventude aos textos de maturidade. $O$

2 Eu tinha publicado esta entrevista em anexo de meu livro Pour une sociologie des intellectuels révolucionnaires: l'évolution politique de Lukács. Paris: Presses Universitaires de France, 1976, p. 292.

3 Eu me permito fazer referência ao meu trabalho (em colaboração com Robert Sayre): Révolte et mélancolie: le romantisme à contre-courant de la modernité. Paris: Payot, 1992.

\begin{tabular}{|l|l|l|l|l|}
\hline Ronita Dialectus & Ano 10 & n. 21 & Janeiro - Abril 2021 & p. $155-161$ \\
\hline
\end{tabular}


princípio esperança é o livro mais importante do filósofo alemão e, sem dúvidas, uma das obras mais importantes do pensamento emancipatório do século XX. Monumental (mais de 1600 páginas), tal livro ocupou o autor durante boa parte de sua vida: escrita durante seu exílio nos Estados Unidos, de 1938 a 1947, a obra será revista uma primeira vez em 1953, e uma segunda em 1959. Após sua condenação como "revisionista" pelas autoridades da República Democrática Alemã, seu autor terminará por deixar o Leste da Alemanha durante a construção do muro de Berlim $(1961)^{4}$.

Ninguém jamais escreveu um livro como esse, misturando, no mesmo sopro visionário, os pré-socráticos e Hegel, a alquimia e os contos de Hoffmann, o orfismo e o messianismo de Shabbataï Tsevi, a filosofia da arte de Schelling e o materialismo marxista, as óperas de Mozart e as utopias de Fourier. Abramos uma página aleatoriamente: encontramos tematizadas questões como o homem da Renascença, o conceito de matéria de Paracelso e Jacob Böhme, a Sagrada família, de Marx, a doutrina do conhecimento, de Giordano Bruno, e o livro sobre o Tratado da reforma do entendimento, de Spinoza. A erudição de Bloch é tão enciclopédica que raros são os leitores capazes de julgar, com conhecimento de causa, cada tema desenvolvido nos três volumes do livro. Seu estilo é frequentemente hermético, mas ele tem uma poderosa qualidade sugestiva: cabe ao leitor filtrar as joias de luz e as pedras preciosas semeadas pela escrita poética, e, por vezes, esotérica, do filosofo ${ }^{5}$.

Diferentemente de outros pensadores de sua geração - a começar por seu amigo György Lukács -, Bloch permaneceu fiel às intuições de sua juventude e jamais negou o romantismo revolucionário de seus primeiros escritos. Encontramos em O princípio esperança frequentes referências à obra $O$ Espírito da Utopia, notadamente a ideia de utopia como consciência antecipadora, como elemento da "pré-aparência" utópica.

A filosofia marxista da esperança de Bloch é antes de tudo uma teoria do aindanão-ser, em suas diversas manifestações: o ainda-não-consciente no ser humano, o ainda-não ocorrido na história, o ainda-não manifestado no mundo. Pois, para o filósofo, o mundo humano está repleto de disposição para algo, de tendência em direção a algo, de latência de algo, sendo esse algo em direção ao qual ele tende resultado da intenção utópica: um mundo livre dos sofrimentos indignos, da angústia, da alienação. Em sua busca das funções antecipadoras do

4 Em dezembro de 1956, no jornal diário do partido oficial, Neues Deutschland, estava escrito: "A filosofia de Bloch serve objetivamente a finalidades políticas reacionárias" (citado em: MÜNSTER, A. Introdução à Tagtraüme von aufrechtem Gang. In: Sechs Interviews mit E. Bloch. Frankfurt: Shurkamp, 1978. p. 11).

5 Ver o artigo de Jack Zipes sobre Bloch em Telos, ${ }^{\circ} 58$, 1983. A página em questão se encontra no capítulo 41 (Les paysages de souhait) do volume II, na seção intitulada Bruno ou l'oeuvre d'art infini.

\begin{tabular}{|l|l|l|l|l|}
\hline Rovista Dialectus & Ano 10 & n. 21 & Janeiro - Abril 2021 & p. $155-161$ \\
\hline
\end{tabular}


espírito humano, o sonho ocupa um lugar importante, desde sua forma mais cotidiana - o sonho acordado - até o sonho "para a frente" inspirado pelas imagens de desejo.

O paradoxo central de $O$ princípio esperança é que este texto potente, inteiramente voltado para o horizonte do futuro, para a frente, para o novum, para o ainda-não-ser, não diz quase nada sobre o ... futuro. $\mathrm{O}$ texto quase nunca ensaia antecipar, prever ou prefigurar a próxima face da sociedade humana - exceto nos termos clássicos da perspectiva marxista: uma sociedade sem classes nem opressão. A ficção científica ou a futurologia moderna de modo algum interessavam Ernst Bloch. Na realidade - à exceção dos capítulos mais teóricos -, o livro é uma imensa e fascinante viagem pelo passado, em busca das imagens de desejo e paisagens da esperança, dispersas nas utopias sociais, médicas, arquiteturais, técnicas, filosóficas, religiosas, geográficas, musicais e artísticas.

Nesta modalidade muito particular da dialética tipicamente romântica entre o passado e o futuro, o desafio é a descoberta de futuro nas aspirações do passado - sob a forma de promessa não cumprida: "As barreiras erguidas entre o futuro e o passado desabam, o futuro não realizado torna-se visível no passado, ao passo que o passado vingado é colhido como herança" (Bloch, 1976, p. 16). Logo, não se trata de afundar no sonho e na melancólica contemplação do passado, mas de fazer do retorno ao passado uma fonte viva para a ação revolucionária, em direção a uma práxis orientada para a realização da utopia.

O complemento necessário do pensamento antecipatório voltado para o mundo vindouro é o olhar crítico para esse mundo: a vigorosa acusação dos males da civilização industrial/capitalista é um dos temas principais (muitas vezes esquecido) de $O$ princípio esperança. Bloch reprova a "pura infâmia" e a "implacável ignomínia" do que ele chama "o atual mundo dos negócios" - um mundo "geralmente plasmado sob o signo da fraude", em que "a sede de lucro sufoca qualquer outro impulso humano". O autor também rechaça as cidades modernas frias e funcionais, que não são mais um lar - Heimat, uma das palavras-chave do livro -, mas "máquinas habitacionais" que reduzem os seres humanos "ao estado de cupins padronizados". Negando todo ornamento e toda linha orgânica, recusando a herança gótica da árvore da vida, as construções modernas parecem o cristal da morte representado pelas pirâmides egípcias. Em última análise, "a arquitetura funcional reflete e mesmo repete o caráter glacial do mundo da automação, de homens divididos pelo trabalho e de uma técnica abstrata" (Bloch, 1976, p. 183; Bloch 1982, p. 204-205, 298, 349-352).

A crítica de Bloch à técnica moderna (capitalista) é motivada, antes de tudo, pela exigência romântica de um relacionamento mais harmonioso com a natureza. A técnica 
burguesa tem uma relação apenas mercantil e hostil com a natureza: a técnica existente "se instala na natureza como um exército que ocupa um país inimigo". Assim como os pensadores da Escola de Frankfurt, o autor de $O$ princípio esperança considera que "o conceito capitalista da técnica como um todo" reflete, frente à natureza, "uma vontade de dominação, uma relação de senhor e escravo". Não se trata, evidentemente, de negar a técnica enquanto tal, mas de opor àquela existente nas sociedades modernas à utopia de uma "técnica da aliança, uma técnica mediatizada com a coprodutividade da natureza", uma técnica "compreendida como libertação e mediatização das criações adormecidas e enterradas no colo da natureza" - fórmula emprestada de Walter Benjamin (como várias vezes ocorreu em Bloch, sem referência de fonte) (cf. Bloch 1982, p. 267, 271, 295, 302, 303).

A grande contribuição do marxismo, segundo Bloch, é a docta spes (douta esperança), a ciência da realidade, o saber ativo voltado à práxis transformadora do mundo e em direção ao horizonte do futuro. Contrariamente às utopias abstratas do passado - que se limitaram a opor sua imagem-desejo ao mundo existente -, o marxismo parte das tendências e das possibilidades objetivas presentes na própria realidade: é essa mediação real que permite o advento da utopia concreta.

Apesar da admiração de Ernst Bloch, na época (antes de 1956), pela União Soviética - e da ausência de crítica em relação ao sistema burocrático e ditatorial que predominava nos países do Leste Europeu -, o filósofo não confundia o "socialismo real" com a utopia concreta. Esta permanecia, em sua visão, uma tendência-latência inacabada, uma imagem-desejo ainda não realizada. Seu sistema filosófico estava inteiramente fundado sobre a categoria do ainda-não-ser, e não sobre a legitimação racional de qualquer Estado "realmente existente".

O marxismo de Bloch era bastante heterodoxo: ainda que Marx tenha se despedido da utopia, e que Engels tenha abordado - em um célebre texto de 1888 - a passagem do socialismo "da utopia à ciência", o autor de $O$ espírito da utopia não hesita em mudar essa ordem. De fato, ele não nega, evidentemente, a necessidade da ciência: o socialismo não pode realizar seu papel revolucionário senão na unidade inseparável da sobriedade e da imaginação, da razão e da esperança, do rigor do detetive com o entusiasmo do sonhador. De acordo com uma expressão tornada célebre, é necessário fundir a corrente fria e a corrente quente do marxismo, ambos igualmente indispensáveis. Todavia, Bloch estabelece entre eles uma hierarquia: a corrente fria existe para a corrente quente, a serviço desta. 
A "corrente quente" do marxismo inspira em Bloch o que ele chama de "otimismo militante", conduzindo a uma esperança ativa no Novum, na realização da utopia. Hans Jonas criticou o que chamou de "otimismo implacável” de Bloch. É verdade que, às vezes, o autor de O princípio esperança parece cair nesse gênero de erro. Entretanto, é justo lembrar que o autor critica muito explicitamente aquilo que ele denomina por "otimismo raso da fé no progresso automático". Considerando que esse falso otimismo tende perigosamente a se tornar um novo ópio do povo, pensa o filósofo que mesmo "uma pitada de pessimismo seria preferível à fé cega e rasa no progresso. Com efeito, um pessimismo ocupado de realismo se deixa menos facilmente surpreender e desorientar pelos reveses e catástrofes". Ernst Bloch insiste, consequentemente, sobre a "característica objetivamente não garantida" da esperança utópica.

Em uma homenagem à Ernst Bloch, Theodor Adorno, um dos pensadores mais pessimistas do século, argumentou que o autor de $O$ princípio esperança foi um dos mais raros filósofos de nossa época que jamais abandonou o pensamento de um mundo sem dominação e sem hierarquia (cf. Adorno, 1971, p. 150).

\section{BIBLIOGRAFIA}

ADORNO, Theodor. Noten zur Literatur (II). Frankfurt: Suhrkamp Verlag, 1971.

BLOCH, Ernst. Le Principe esperance (tome I). Trad. de l' allemand par Françoise Wuilmart. Paris: Gallimard, 1976.

Paris: Gallimard, 1982.

Le Principe esperance (tome II). Trad. de 1' allemand par Françoise Wuilmart.

Geist der utopie. Frankfurt: Suhrkamp, 1964/1980.

L'Esprit de l'utopie. Trad. de l'allemand par Anne-Marie Lang et Catherine Piron-Audard. Paris: Gallimard, 1977.

LÖWY, Michael. Pour une sociologie des intellectuels révolucionnaires: l'évolution politique de Lukács. Paris: Presses Universitaires de France, 1976.

Paris: Payot, 1992.

Révolte et mélancolie: le romantisme à contre-courant de la modernité.

LÖWY, M. Utopía y romanticismo revolucionario en Ernst Bloch. In: VEDDA, Miguel (org.) Ernst Bloch - Tendencias y latencias de un pensamiento. Buenos Aires: Herramienta Ediciones, 2007, pp. 13-21.

\begin{tabular}{|c|c|c|c|c|}
\hline Qenista Dialectus & Ano 10 & n. 21 & Janeiro - Abril 2021 & p. $155-161$ \\
\hline
\end{tabular}


MÜNSTER, Arno. Int. à Tagtraüme von aufrechtem Gang. In: Sechs Interviews mit E. Bloch. Frankfurt: Shurkamp, 1978. 